\title{
Simulation to Interior Microclimate of Swimming Hall under Different Seat Arrangements and Partition
}

\author{
Deming Liu ${ }^{1, \mathrm{a}}$, Ge Yu ${ }^{1, \mathrm{~b}}$ and Yu Dong ${ }^{1, \mathrm{c}}$ \\ ${ }^{1}$ School of Architecture, Harbin Institute of Technology, Room 130, No.66 West Dazhi Street, Nan \\ Gang District, Harbin, Heilongjiang Province, China, 150001 \\ aliudeming@hit.edu.cn, ’947603666@qq.com, dongyu_hit@163.com
}

Keywords: swimming hall; thermal comfort; seat arrangement; partition

Abstract. In large swimming hall for international events, seat arrangement and partition could affect indoor thermal environment. In this paper, a 4480 seats swimming hall was selected as the typical study object. Then different seat arrangements of swimming hall during competition events were summarized. Simulation experiments of single model were conducted through software of Airpak as research platform. After each experiment, results of temperature, relative humidity, speed and mean age of air, PMV and PPD of the space in Airpak post item were collected and recorded as experiment data. Optimal solution is proposed in aspect of thermal comfort.

\section{Introduction}

Large-scale swimming hall refers to those with 3000-6000 spectators' seats, for both major competitions events and after-event uses. The interior microclimate reflects whether comfort level and physical conditions of competition hall fulfills requirements. CFD simulation is a relatively efficient and reliable indoor microclimate evaluation method $[1,2]$. It has been applied to simulation of air condition in various spaces including swimming hall and has been verified and validated by many researchers [3, 4]. However, research on effects of space arrangements to indoor microclimate is quite rare. In large swimming hall for international events, seat arrangement and partition could affect indoor thermal environment. In this paper, the arrangement of a 4480 seating swimming hall is defined as the basic research object. Basic inner space arrangement were summarized and simplified from case-study of swimming center of the 2010 Asian Games in Guangzhou. Other seat arrangements were compared based on other large natatoriums. Ideal partition was also considered. Then abstract them into 6 models to be simulated through software of Airpark. After simulation results were compared to determine optimal solution of thermal comfort.

Basic Arrangement of Simulation Subjects. The research took rectangle competition hall used in summer as basic study subject, which contains a standard diving pool and a standard swimming pool. The space geometrical data is dimensioned in Fig. 1.

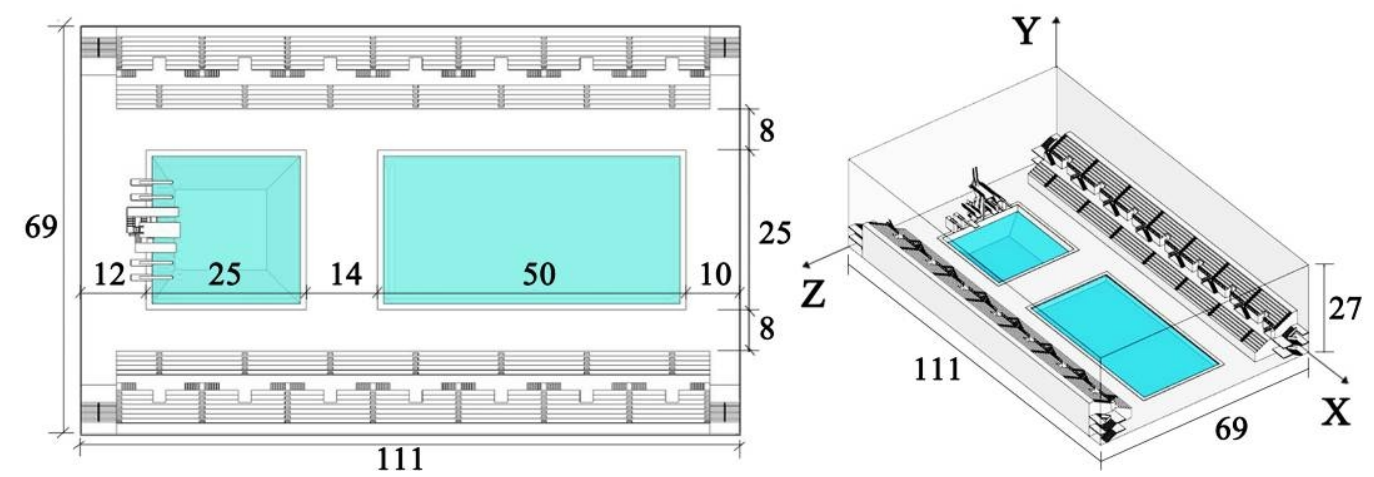

Fig. 1. Geometrical data of basic study subject (m)

Compared Arrangements. To study microclimate affected by seat arrangement and the existence of partition, 6 models were established. The hall was assumed to be used in daytime, with $60 \%$ of audience seats occupied. This group included 6 arrangement types, of which the space variable 
quantity and related model names are listed in Table 1 and illustrated in Fig. 2. Among the 6 model, $\mathrm{A} 4, \mathrm{~A} 5$ and A6 were based on A1, A2 and A3, adding transparent adiabatic partition between seat and pool area , which were 27 meters high.

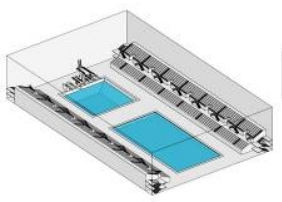

A1

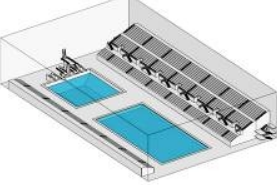

A2

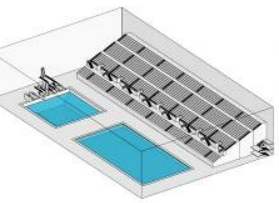

A3

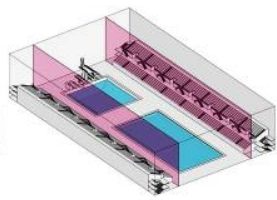

A4

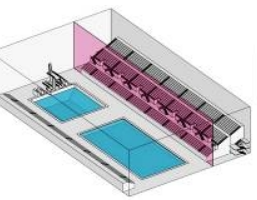

A5

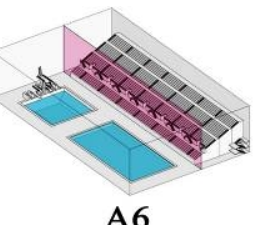

A6

Fig. 2. Seat and partition arrangement

Table 1. Arrangement type

\begin{tabular}{|c|c|c|c|c|c|c|}
\hline Rows & \multicolumn{2}{|c|}{14 rows +14 rows } & \multicolumn{2}{|c|}{6 rows+22 rows } & \multicolumn{2}{c|}{28 rows on one side } \\
\hline Partition & $\times$ & $\sqrt{ }$ & $\times$ & $\sqrt{ }$ & $\times$ & $\sqrt{ }$ \\
\hline Model & A1 & A4 & A2 & A5 & A3 & A6 \\
\hline
\end{tabular}

\section{Simulation}

Basic model description. Simulation models were abstracted and simplified from space arrangements mentioned above in XYZ coordinate system. Each row of audience seat was equivalent to a heat source block with $6720 \mathrm{~W}$ radiation on top side.

Boundary condition. Simulation was assumed in summer condition with temperature of $30^{\circ} \mathrm{C}$ in daytime. Surrounding interface was assumed effective thick surface of which outside surface temperature and environmental temperature were consistent. The special heat transfer property wasn't considered. The ideal gas pressure was $1.01325 \times 10^{5} \mathrm{~N} / \mathrm{m}^{2}$. Gas density was $1.225 \mathrm{~kg} / \mathrm{m}^{3}$. Gravitational acceleration was $9.80665 \mathrm{~m} / \mathrm{s}^{2}$ on $-\mathrm{Y}$ direction. Air zoning was applied as air conditioning method, combined with vertical air curtain separating pool and seat area. Two pools were equivalent to air intakes with temperature of $27^{\circ} \mathrm{C}$, speed of $0.1 \mathrm{~m} / \mathrm{s}$ and relative humidity of $90 \%$. Positions of simplified actual air intakes and vents are illustrated in Fig. 3. Parameters of them are listed in Table 2. Each row of seat was equivalent to a heat source block with $6720 \mathrm{~W}$ radiation on top side.
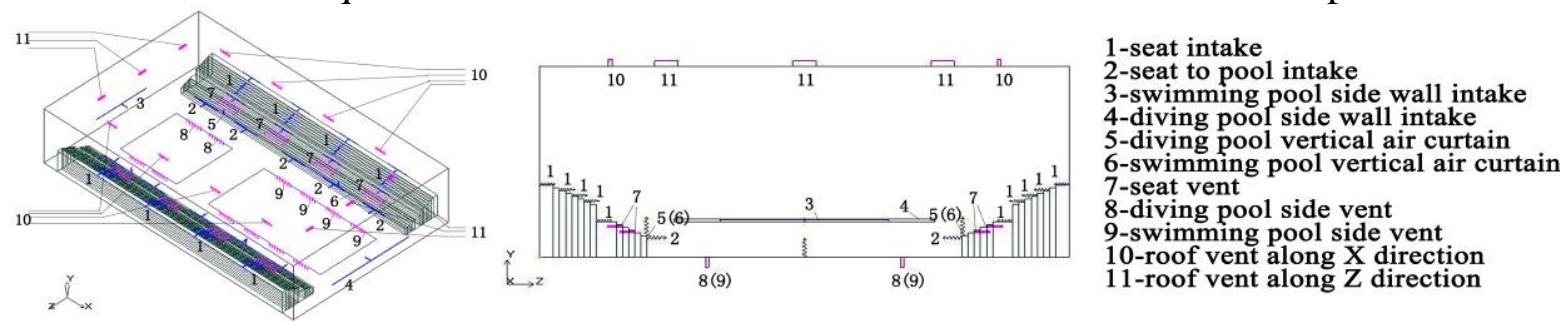

Fig. 3. Positions of air intakes and vents

Table 2. Parameters of air intakes and vents

\begin{tabular}{|c|c|c|c|c|c|c|c|c|c|c|c|}
\hline No. & 1 & 2 & 3 & 4 & 5 & 6 & 7 & 8 & 9 & 10 & 11 \\
\hline Temp $\left({ }^{\circ} \mathrm{C}\right)$ & 20 & 23 & 23 & 23 & 23 & 23 & - & - & - & - & - \\
\hline Speed $(\mathrm{m} / \mathrm{s})$ & 0.2 & 2.26 & 2 & 2 & 2 & 2 & - & - & - & - & - \\
\hline
\end{tabular}

Mathematic model and Basic parameter setting. The research took Indoor-zero Equation model as turbulence model, which expresses turbulent viscosity by functions of local mean velocity and turbulence length scale. Original classical Indoor-zero Equation is:

$$
\mu_{\mathrm{t}}=\mathrm{c} \rho \mathrm{K}^{0.5} \mathrm{~L}
$$


The proposed simplified formula from it is:

$$
\mu_{\mathrm{t}}=0.03874 \rho v 1 \text {. }
$$

In Eq. 1 and Eq. 2, $\mu_{t}=$ turbulent viscosity; $c=$ empirical constant; $\rho=$ fluid density; $K=$ turbulent kinetic energy; $\mathrm{L}=$ turbulent pulse length scales; $v=$ local mean velocity; $1=$ distance from nearest wall.Generating mesh type of models was hexa Cartesian. Mesh parameters form was normal. Unit was metre and max size ratio was 2. Max X size was 5.55 while max $Y$ size 1.35 and max $Z$ size 3.45. Mesh density of intakes and vents was separately increased according to generating tests. Number of iterations was 1000. Pressure under-relaxation was 0.7 while momentum under-relaxation was 0.3.

\section{Results Analysis and Discussion}

Results and analysis. Horizontal and vertical plane cuts of temperature, relative humidity, air speed, mean age of air, PMV and PPD of the space were collected as experiment results. Result values were approximate average value derived from certain compared areas of plane cut results. Relative Humidity was abbreviated to RH and Mean Age of Air abbreviated to MAA.Firstly models without partition (A1, A2, A3) were compared. Cut plane position depends on various user groups. $Y=0.5 \mathrm{~m}$ plane was selected for comfort evaluation of swimmers, $Y=1.5 \mathrm{~m}$ for people on the deck while $\mathrm{X}=55.5 \mathrm{~m}$ for the audience. Compared areas are illustrated in Fig. 4 and values are listed in Fig. 5.

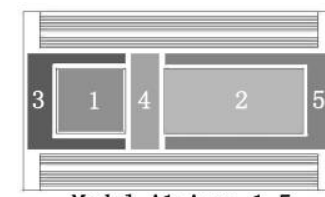

Model A1:Area 1 5

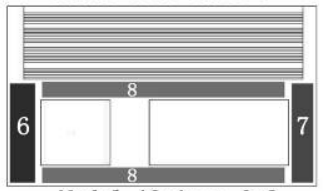

Model A3:Area 6 8

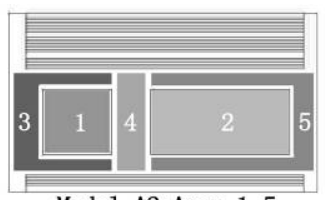

Mode1 A2:Area 1 5

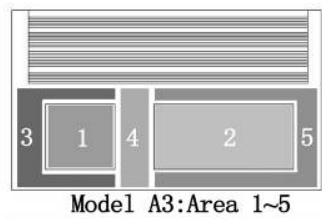

Model A3:Area 1 5

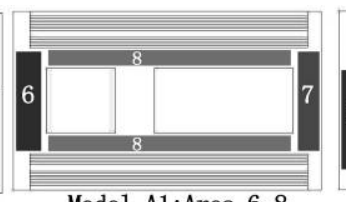

Mode1 A1:Area 6 8

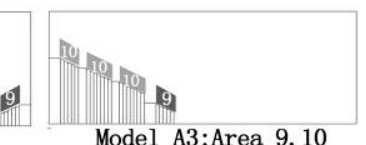

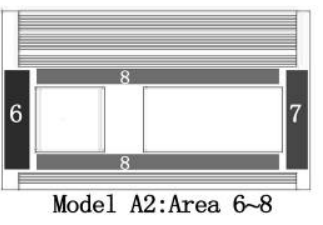

Area 1 2: $\mathrm{Y}=0.5 \mathrm{~m}$ Area 3 8: $\mathrm{Y}=1.5 \mathrm{~m}$

Area 9 10: $\mathrm{X}=55.5 \mathrm{~m}$

Fig. 4. Compared areas of no-partition models
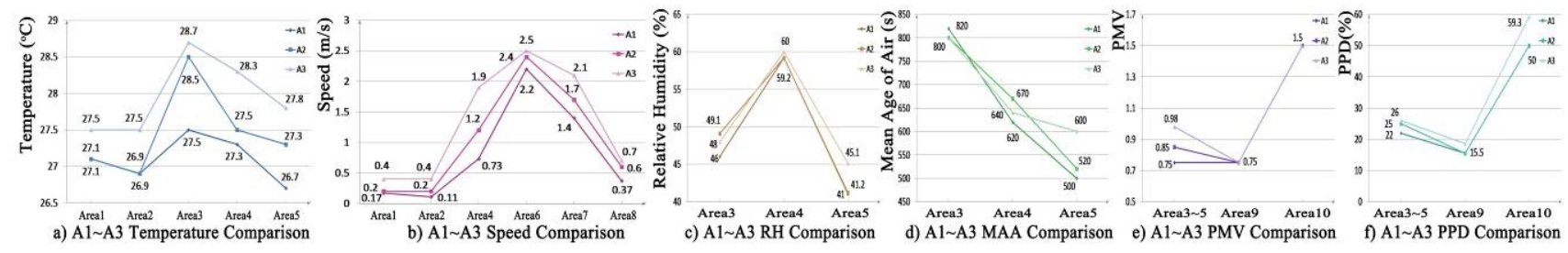

Fig. 5. Data of no-partition models

Models with partition (A4, A5 and A6) were compared with corresponding models without partition in aspect of change value of temperature and relative humidity difference between pool area and audience area affected by partition. Cut plane $X=55.5 \mathrm{~m}$ was selected as results in Fig. 6 and Fig. 7 . Compared areas are 0 3m height zones above pool and seat. For each model, difference value of temperature or relative humidity between pool zone and seat zone were calculated. Pool area temperature decreased slightly after adding partition but audience area temperature increased drastically. Temperature difference between two areas increased distinctly as shown in Fig. 6. Pool area relative humidity increased slightly after adding partition but audience area temperature decreased drastically as shown in Fig. 7. Relative humidity difference between two areas increased distinctly.

Among the three seat arrangement types, symmetric seat arrangement model was most obviously affected by partitions which were shown by change value from A1 to A4 in aspects of both temperature difference and relative humidity difference. 

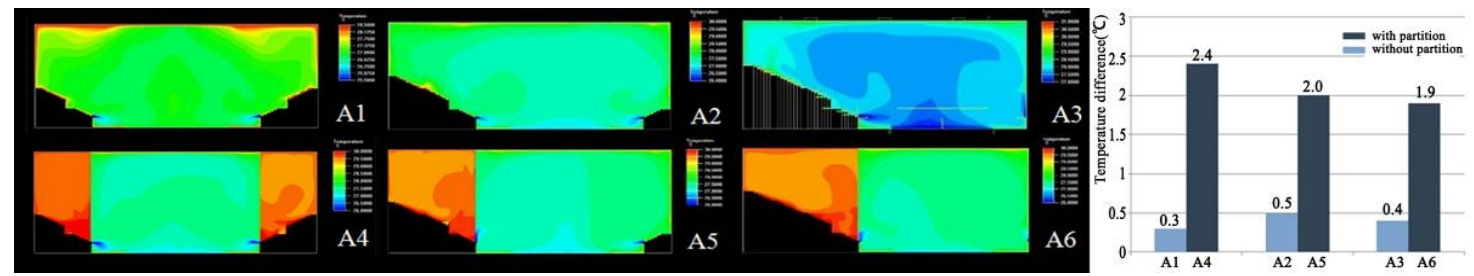

Fig. 6. Temperature cut plane and temperature difference between pool and seat zone
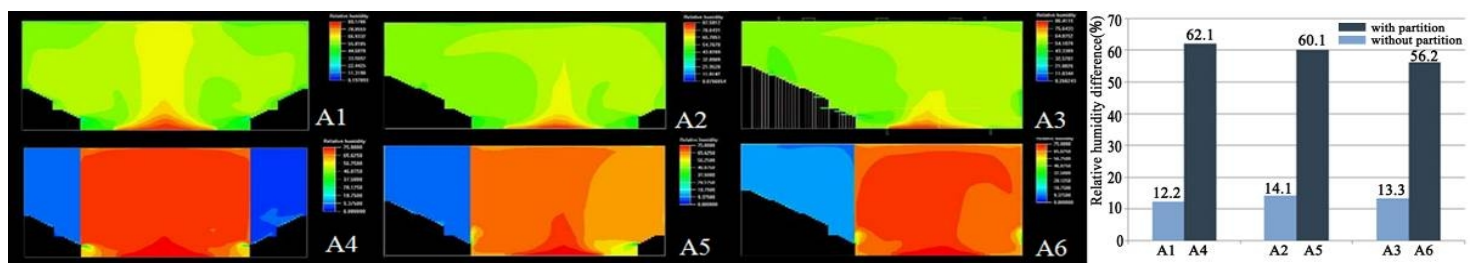

Fig.7. Relative humidity cut plane and relative humidity difference between pool and seat zone

Results discussion. According to Standard JGJ31-2003, temperature of pool area and audience area should be $26 \sim 29{ }^{\circ} \mathrm{C}$ while relative humidity $60 \% \sim 70 \%$ in summer condition. Speed of pool area should be less than $0.2 \mathrm{~m} / \mathrm{s}$ and audience area less than $0.5 \mathrm{~m} / \mathrm{s}$. According to Standard GB50736-2012, PMV should be $-0.5 \sim+0.5$ while PPD less than $10 \%$. From simulation results, we can see model A1 meets the standard best. It is the optimal solution of no-partition arrangements. We can also see partition could effectively separate temperature and humidity between different areas. But ideal transparent partition material is not available under existent tech level, which makes partition adverse for utilization considering sight quality of audience.

\section{Conclusions}

From analysis upon simulation results, the following conclusions can be made: Under competition condition, symmetric seat arrangement is the optimal solution. Partition could effectively separate temperature and humidity between different areas which is benefit to zone controlling and symmetric seat arrangement was the most sensitive to this change. But sight quality of audience will be decrease for the lack of ideal transparent partition material.

\section{Acknowledgements}

The National Natural Science Foundation of China (Grant No. 51208132) and the 54th China Postdoctoral Science Foundation of China (2013M 541380) support this paper.

\section{References}

[1] Hiyama, Kyosuke; Ishida, Yoshihiro; Kato, Shinsuke, Building simulation of thermal environment using response factor analyzed by three-dimensional CFD. IBPSA 2009 - International Building Performance Simulation Association 2009, p 474-480.

[2] Asawa, Takashi (Tokyo Institute of Technology, Yokohama, Japan); Hoyano, Akira, High-resolution heat balance simulation for building and urban surfaces by combining the 3D cad-based thermal environment simulator and CFD .Proceedings of Building Simulation 2011: 12th Conference of International Building Performance Simulation Association, 2011 , p 2565-2572.

[3] Hiroyoshi Aizawa, Hiroshi Yoshino, Jing Liu, CFD prediction of surface condensation on walls and its experimental validation. Building and Environment. 2004(39), p905-911.

[4] Joseph C. Lam, Apple L.S. Chan, CFD analysis and energy simulation of a gymnasium. Building and Environment, 2001(36), p351-358. 